\title{
Application of gyrotheodolites in the determination of bearings for the hozirontal control network of Nui Beo underground coal mine
}

\author{
Dung Ngoc Vo ${ }^{1}$, , Canh Van Le ${ }^{1}$, Dung Tien Nguyen ${ }^{2}$, Tu Anh Nguyen ${ }^{3}$ \\ ${ }^{1}$ Hanoi University of Mining and Geology, Hanoi, Vietnam \\ 2 Nuibeo Coal Joint Stock Company - Vinacomin, Quang Ninh, Vietnam \\ 3 Vietbac Mining Industry Holding - Vinacomin, Hanoi, Vietnam
}

\begin{tabular}{l} 
ARTICLE INFO \\
Article history: \\
Received 25th Sept. 2021 \\
Revised 09th Jan. 2022 \\
Accepted 04 \\
\hline Keywords: \\
Gyrotheodolites, 2022 \\
Mine orientation, \\
Nui Beo coal mine, \\
Underground control network.
\end{tabular}

\section{ABSTRACT}

In Vietnam, coal mines are exploited deeper and deeper, and the method of seams opening using with mine shafts has been increasingly popular. For mine surveying, there are several methods of conveying the bearing to the tunnels, depending on the number of mine shafts, the depth and the cross-section of the shaft, and the available surveyring equipment of the mine. Each method has its advantages and disadvantages, and different application conditions. It has been proved that the method of conveying the bearing to the tunnels or underground orientation by traditional methods gives low accuracy, requires a lot of time and effort, and no assurance of accuracy. The method using a gyrotheodolite has the advantages of reducing time and effort and improving the level of safety. Therefore, the application of surveying gyro is considered as an effective alternative in this work. The paper presents the results of the application of a GYRO X II gyrotheodolite in determining bearings at $-140 \mathrm{~m}$ and -350 $m$ of the Nui Beo coal mine in order to improve orientation accuracy. The resulting bearings of the first lines of the 2-level underground traversing control networks were used to determine control points at the $-140 \mathrm{~m}$ level and the $-350 \mathrm{~m}$ level. The results proved the accuracy of the method with the biggest azimuth error of 9.23", meeting the accuracy requirement of the Vietnamese standard for mine surveying.

${ }^{*}$ Corresponding author

E - mail: vongocdung@humg.edu.vn

DOI: 10.46326/JMES.2022.63(1).07 


\title{
Tạp chí Khoa học Kỹ thuật Mỏ - Địa chất
}

Trang điện tử: http://tapchi.humg.edu.vn

\section{Ứng dụng máy kinh vĩ con quay trong công tác đo chuyền phương vị cho lưới khống chế toạ độ phẳng mỏ than Núi Béo}

\author{
Võ Ngọc Dũng ${ }^{1,}{ }^{*}$, Lê Văn Cảnh ${ }^{1}$, Nguyễn Tiến Dụng ${ }^{2}$, Nguyễn Anh Tú 3 \\ 1. Trường Đại học Mỏ - Đị chất, Hà Nội, Việt Nam \\ 2. Công ty Than Núi Béo - Vinacomin, Quảng Ninh, Việt Nam \\ 3. Tổng công ty Công nghiệp Mỏ Việt Bắc - Vinacomin, Hà Nội, Việt Nam
}

THÔNG TIN BÀI BÁO TÓM TẮT

Quá trình:

Nhận bài 25/9/2021

Sửa xong 09/01/2022

Chấp nhận đăng 04/02/2022

Tù̀ khóa:

Đo liên hệ,

Lưới khống chế hầm lò.

Máy kinh vĩ con quay,

Mỏ than Núi Béo.
Ở Việt Nam, các mỏ than hầm lò khai thác ngày càng xuống sâu, phương pháp mở vỉa bằng giếng đứng đang trở nên phổ biến. Tuỳ thuộc vào sốlượng giếng đúng, độ sâu, trinh độ trang thiết bi đo đạc hiện có của mỏ mà công tác đơ chuyền phương vị và toạ độ có thể tiến hành bằng nhiều phương pháp khác nhau. Mối phưong pháp đều có ưu nhược điểm và điều kiện úng dụng khác nhau. Kết quả khảo sát và phân tích lý thuyết đã khẳng định rằng: Công tác đo nối chuyền phương vi xuống hầm lò bằng các phương pháp đo liên hê truyền thống tốn nhiều thời gian, công sức lao động và độ chính xác thấp. Sứ dung máy kinh vĩ con quay đo chuyền phương vi trong mỏ hầm lò được xem là định hướng đúng, giải pháp hiệu quả để khẳc phục các nhwợc điểm của phương pháp truyền thống. Bài báo trình bày kết quả úng dụng máy kinh vĩ con quay GYRO XII trong công tác đo liên hệ mặt bẳng qua giếng đúng xuống hầm lò tai múc $-140 \mathrm{~m}$ và $-350 \mathrm{~m}$ ở mỏ than Núi Béo nhằm nâng cao độ chính xác đo chuyền phương vị cạnh đầu tiên của mạng lưới khống chế cơ sở dưới hầm lò, giảm thời gian, công sức và nâng cao múcc độ an toàn lao động. Thành quả phương vị đo chuyền xuống lò được úng dụng trong thành lập đường chuyền cơ sở cấp 2 mỏ hầm lò tại múc $-140 m$ và $-350 m$ với sai số góc phương vị yếu nhất của đường chuyền tương ứng là 9,23" đạt độ chính xác theo tiêu chuẩn Việt Nam về trắc địa mỏ.

(C) 2022 Trường Đại học Mỏ - Địa chất. Tất cả các quyền được bảo đảm.

\section{Mở đầu}

Hiện nay, các mỏ than hầm lò tại Việt Nam khai thác ngày càng xuống sâu, công tác mở vỉa bằng lò bằng và giếng nghiêng đã không còn phù

\footnotetext{
*Tác giả liên hệ

E - mail: vongocdung@humg.edu.vn DOI: 10.46326/JMES.2022.63(1).07
}

hợp, thay thế vào đó, mở vỉa bằng giếng đứng là phương pháp đang dần được áp dụng rộng rãi (Võ \& Nguyễn, 2020). Các mỏ hầm lò mở vỉa bằng giếng đứng có độ sâu lớn điển hình như: mỏ than Hà Lầm, mỏ than Núi Béo và gần đây nhất là mỏ than Hạ Long, với chiều sâu giếng tương ứng là $450 \mathrm{~m}, 400 \mathrm{~m}$ và $700 \mathrm{~m}$.

Đo liên hệ mặt bằng (hay đo định hướng mặt bằng) là công tác trắc địa nhằm thống nhất hệ tọa độ trắc địa dưới hầm lò với hệ tọa độ trắc địa trên 
mặt đất (Võ, 2016). Kết quả cuối cùng của công tác định hướng mặt bằng qua một giếng đứng là cho phương vị một cạnh và tọa độ 1 điểm dưới hầm lò. Sai số của công tác này ảnh hưởng trực tiếp tới kết quả công tác trắc địa trong mỏ hầm lò, như kết quả đào sân ga dưới giếng, phát triển cho hướng đào lò nối thông các giếng đứng. Do vậy, việc nghiên cứu các nguồn sai số ảnh hưởng đến độ chính xác công tác định hướng mặt bằng cũng như các biện pháp kỹ thuật khắc phục sai số, nâng cao độ chính xác công tác này luôn là vấn đề được thực tế sản xuất và các nhà khoa học quan tâm. Tác giả Võ Chí Mỹ và đồng nghiệp đã phân tích các nguồn sai số ảnh hưởng đến công tác đo định hướng. Nghiên cứu này đã khẳng định sai số về góc phương vị khi tính chuyền xuống lò có ảnh hưởng lớn đến độ chính xác của mạng lưới hầm lò và khoảng cách giữa hai dây quả nặng càng lớn, sai số chuyền phương vị càng nhỏ (Võ \& Lê, 2013). Trong các nghiên cứu (Jabłoński, 2019; Černota và nnk., 2013; Phạm, 2013) các tác giả chỉ tập trung vào nâng cao hiệu quả công tác đo chuyền tọa độ điểm xuống lò, không đề cập đến yếu tố góc phương vị. Trong nghiên cứu công bố năm 2014, tác giả Lê Văn Cảnh và đồng nghiệp đã khẳng định công tác đo liên hệ theo phương pháp truyền thống tại Việt Nam không đảm bảo độ chính xác khi giếng có độ sâu lớn và đã đề xuất sử dụng máy kinh vĩ con quay trong đo nối phương vị tại giếng đứng có độ sâu lớn tại mỏ than Hà Lầm (Lê \& Nguyễn, 2014). Hai năm sau đó, cũng tại mỏ Hà Lầm, các tác giả này đã đề xuất ứng dụng máy kinh vĩ con quay xác định góc phương vị nhằm nâng cao độ chính xác công tác trắc địa trong đào lò đối hướng (Lê \& Nguyễn, 2016) cho sai số thông hướng đạt độ chính xác đến $\mathrm{cm}$. Trong một nghiên cứu khác năm 2016, tác giả Nguyễn Viết Nghĩa và các cộng sự đã khẳng định ứng dụng máy kinh vĩ con quay có thể giảm thiểu sai số vị trí mặt bằng cho lưới khống chế hầm lò (Nguyễn \& Võ̃, 2016). Từ các nghiên cứu trên, cho thấy ứng dụng máy kinh vĩ con quay là giải pháp hữu hiệu, phù hợp với công tác đo liên hệ mặt bằng qua giếng đứng tại Việt Nam. Hiện nay, mỏ than Núi Béo khai thác than hầm lò từ mức $+35 \mathrm{~m}$ xuống mức $-350 \mathrm{~m}$. Hệ thống đường lò mới xây dựng, chưa có mốc tọa độ và độ cao phục vụ các công tác đào lò đối hướng, cập nhật và công tác trắc địa khác (Công ty cổ phần Địa chất Mỏ). Do đó, cần thiết phải thành lập ngay hệ thống mốc khống chế cơ sở tại các đường lò chính tại mức -140 m và -350 m, tương ứng với chiều sâu giếng là $175 \mathrm{~m}$ và $385 \mathrm{~m}$. Hệ thống mốc khống chế này làm cơ sở để cho hướng đào lò đối hướng giữa giếng chính, giếng phụ và các thượng khai thác, thông gió và mặt bằng cửa lò từ mức $+35 \div-350 \mathrm{~m}$. Chiều dài đường lò có thể lên tới vài km, khi đó sai số góc phương vị gốc sẽ ảnh hưởng tới kết quả cho hướng đào lò. Sai số vị trí thông hướng lên tới 2,4 m khi áp dụng biện pháp kỹ thuật truyền thống đo liên hệ mặt bằng xác định phương vị cạnh gốc đầu tiên lưới hầm lò phục vụ đào lò đối hướng tại mỏ than Hà Lầm (Lê \& Nguyễn, 2014). Do vậy, tại mỏ Núi Béo nghiên cứu và đưa ra biện pháp kỹ thuật phù hợp trong đo liên hệ mặt bằng qua giếng đứng, làm cơ sở dữ liệu gốc tin cậy, đảm bảo độ chính xác cho hướng đào lò đối hướng ở các đường lò có chiều dài lớn.

\section{Nguyên lý xác định phương vị bằng máy kinh vĩ con quay}

Góc phương vị tọa độ của đường thẳng (góc phương vị cạnh) là góc hợp bởi hướng bắc của kinh tuyến trục tới hướng đường thẳng theo chiều quay kim đồng hồ (Võ, 2009). Vậy để đo được góc phương vị cần phải xác định được hướng bắc của hệ trục tọa độ. Máy kinh vĩ con quay hoạt động theo nguyên lý: thiết bị con quay, quay quanh trục quay tự do (trục đứng của máy) có tốc độ góc đủ lớn (>20.000 vòng/phút thì vị trí cân bằng của nó luôn nằm trong mặt phẳng kinh tuyến đi qua điểm treo (điểm đặt máy) (Nguyễn và nnk., 1998). Trên nguyên lý như vậy, để xác định phương vị một cạnh, cần xác định vị trí cân bằng của trục quay và góc hợp bởi trục này với cạnh cần xác định phương vị. Từ đó tìm được góc phương vị từ vị trí đặt máy, tính chuyển kinh tuyến từ sang kinh tuyến trục thông qua độ lệch từ thiên $(\delta)$ tìm được góc phương vị của cạnh cần đo. Qui trình đo chuyền phương vị cho cạnh đầu tiên của lưới hầm lò theo nguyên lý này được tuân theo qui trình sau: Trên mặt đất đặt máy kinh vĩ con quay tại mốc gốc $A$ (Hình 1), đo được góc phương vị từ cho cạnh $\mathrm{AB}$ được $\alpha_{\mathrm{AB}}, \mathrm{AB}$ là cạnh gốc đã biết góc phương vị $\alpha_{\mathrm{AB}}$. Độ lệch từ thiên được xác định theo công thức (1).

$$
\delta=\alpha_{A B^{\prime}}-\alpha_{A B}
$$

Dưới hầm lò, đặt máy kinh vĩ con quay tại điểm C (Hình 1), đo được góc phương vị từ cho cạnh CD dưới hầm lò được tính theo công thức (2) 


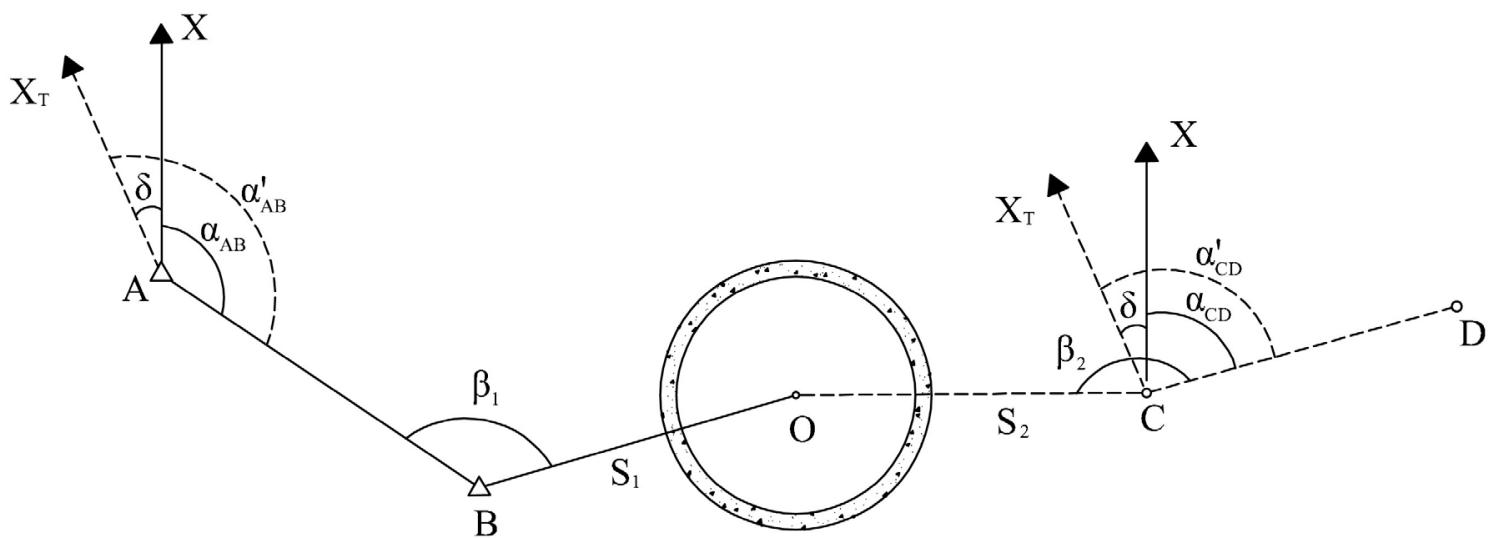

Hình 1. Sơ đồ đo liên hệ qua giếng đứng sử dụng máy kinh vĩ con quay.

(X-Kinh tuyến trục; $X_{T}$ - kinh tuyến tù̀; $\delta$ - độ tù̀ thiên; $\alpha_{A B}^{\prime}$ - phương vị cạnh $A B$ trên mặt bằng mỏ đo bằng máy kinh vĩ con quay; $\alpha_{A B}$ - phương vị cạnh $A B$ tính được tù̀ tọa độ hai điểm gốc $A, B ; \beta_{1}, \beta_{2}$ - các góc bằng cần đo; $S_{1}, S_{2}$ - chiều dài các cạnh cần đo; $\alpha_{C D}^{\prime}$ - phương vị cạnh $C D$ dưới lò đo bằng máy kinh vĩ con quay; $\alpha_{C D}$ - phương vị cần tìm của cạnh $C D$ ).

$$
\alpha_{C D}=\alpha_{C D^{\prime}}+\delta
$$

\section{3. Ứng dụng máy kinh vĩ con quay đo chuyền phương vị qua giếng đứng tại mỏ than Núi Béo}

\subsection{Yêu cầu đo nối}

Để có cơ sở thành lập lưới khống chế hầm lò tại các mức -140 m và -350 m ở mỏ than Núi Béo, công tác đo định hướng xuống giếng cần đạt độ chính xác: đo nối tọa độ đến các mốc tiệm cận miệng giếng trên mặt đất đạt lưới giải tích 1, sau khi đo nối tính chuyển xuống lò, tọa độ điểm đầu tiên và phương vị cạnh đầu tiên của lưới hầm lò có độ chính xác đạt lưới giải tích 2 (Công ty cổ phần Địa chất Mỏ, 2020).

\subsection{Máy kinh vĩ con quay}

Máy kinh vĩ con quay GYRO X II của hãng SOKKIA (Hình 2) được sử dụng để đo chuyền phương vị xuống lò tại mỏ than Núi Béo.

Hệ thống con quay hồi chuyển cho phép máy GYRO X II xác định hướng bắc thực với độ chính xác đạt \pm 15 ". Tại mọi vị trí đặt máy GYRO X II có thể xác định phương vị cạnh cần đo trong thời gian 19 phút (Topcon, 2021). Với độ chính xác và thời gian này, có thể thấy ứng dụng GYRO X II cho phép tăng hiệu quả công tác đo chuyền phương vị, giảm thời gian và công sức, nâng cao điều kiện an toàn lao động.
Bảng 1. Thông số kỹ thuật chính máy GYRO X II.

\begin{tabular}{|c|c|c|}
\hline TT & Thông số chính & Độ chính xác \\
\hline 1 & $\begin{array}{c}\text { Độ chính xác đo góc } \\
\text { phương vị }\end{array}$ & $\pm 15^{\prime \prime}$ \\
\hline 2 & Độ chính xác đo góc bằng & $\pm 1^{\prime \prime}$ \\
\hline 3 & Độ chính xác đo chiều dài & $\begin{array}{c}1,5 \mathrm{~mm}+2 \\
\text { ppm.D }\end{array}$ \\
\hline 4 & Nhiệt độ hoạt động & $-20 \div+50^{\circ} \mathrm{C}$ \\
\hline
\end{tabular}

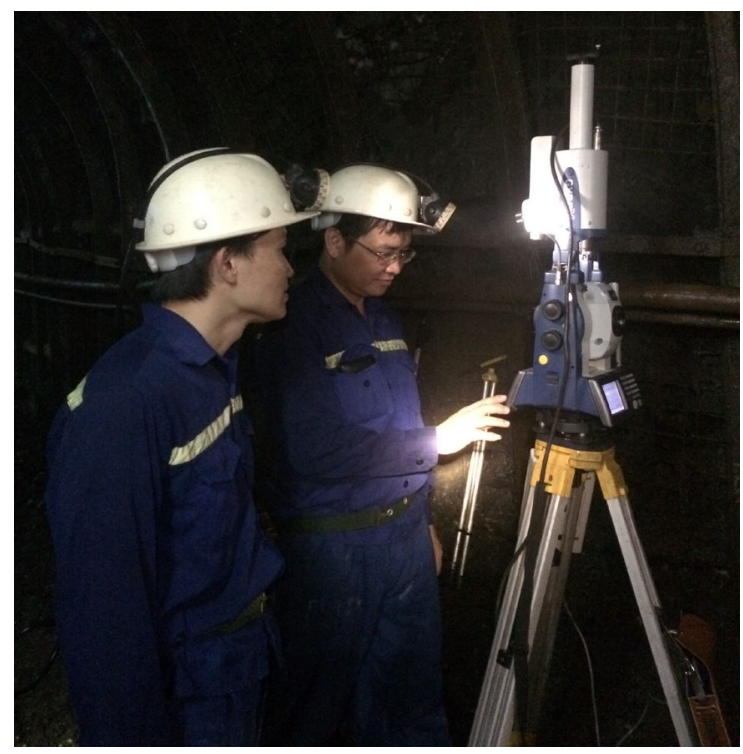

Hình 2. Máy kinh vĩ con quay GYRO X II trên trạm đo phương vị trong mỏ than Núi Béo. 


\section{3. Đo đạc thực nghiệm}

Sơ đồ đo liên hệ mặt bằng qua giếng đứng tại mỏ than Núi Béo được tiến hành với quá trình chiếu điểm một dây dọi được mô tả trên Hình 3. Dây dọi được sử dụng là cáp Inva, treo một đầu vào ròng rọc trên tháp giếng, đầu còn lại được treo dây quả nặng và đặt vào thùng dầu để tránh dao động.

Trên mặt đất, tọa độ dây quả nặng (0) được đo nối với hai điểm mốc tam giác hạng IV (GPS4 và GPS3) bằng phương pháp giao hội góc cạnh (Hình 3). Các phép đo được thực hiện với chỉ tiêu kỹ thuật lưới giải tích 1. Đặt máy GYRO X II tại điểm mốc GPS4 tiến hành đo góc phương vị con quay của cạnh (GPS4 - GPS3). Tại mức -140 m dưới hầm lò, đặt máy GYRO X II tại điểm mốc BN23A để xác định phương vị cho cạnh BN23A-BN24 và B23A$\mathrm{O}_{1}$, đo góc bằng $\beta_{3}$ làm cơ sở kiểm tra việc đo phương vị. Tương tự như vậy, tại mức $-350 \mathrm{~m}$, máy GYRO X II tại điểm mốc BN43 đo góc phương vị cạnh $\mathrm{BN} 43-\mathrm{BN} 42, \mathrm{BN} 43-\mathrm{O}_{2}$ và góc bằng $\beta_{4}$. Cùng với việc đo góc, các cạnh cần thiết $S_{1}, S_{2}, S_{3}$ và $S_{4}$ cũng được đo để làm cơ sở truyền tọa độ.
3.4. Xử lý dũ̃ liệu xác định phương vị cho các cạnh dưới đưòng lò

Độ lệch từ thiên được xác định theo công thức (1) kết quả ghi trong Bảng 2.

Tính phương vị cạnh dưới hầm lò tại mức $140 \mathrm{~m}$ và $-350 \mathrm{~m}$ theo công thức (2). Tai mức -140 m, góc kẹp $\beta_{3}$ đã đo được là 209034'53", tại mức $350 \mathrm{~m}$ góc kẹp $\beta_{4}$ đã đo được là 169040'36". Hai góc này có thể tính từ góc phương vị đã đo được trong Bảng 2 theo công thức sau:

$$
\begin{gathered}
\beta_{3}=\alpha_{B N 23 A-B N 24}-\alpha_{B N 23 A-O_{1}}+180^{\circ} \\
=209^{0} 34^{\prime} 59^{\prime \prime} \\
\beta_{4}=\alpha_{B N 43-B N 42}-\alpha_{B N 43-O_{2}}+180^{\circ} \\
=169^{0} 40^{\prime} 32^{\prime \prime}
\end{gathered}
$$

Kết quả trên cho thấy độ lệch góc kẹp đo bằng máy toàn đạc với kết quả tính toán từ phương vị đo bằng GYRO X II là rất nhỏ, chỉ mới -06" ở mức $140 \mathrm{~m}$ và -04 " ở mức $-350 \mathrm{~m}$.

\section{5. Úng dụng kết quả đo phưong vị thành lập lưới đường chuyền hầm lò}

Sau khi xác định được góc phương vị cạnh đầu tiên của lưới khống chế dưới hầm lò ở các mức

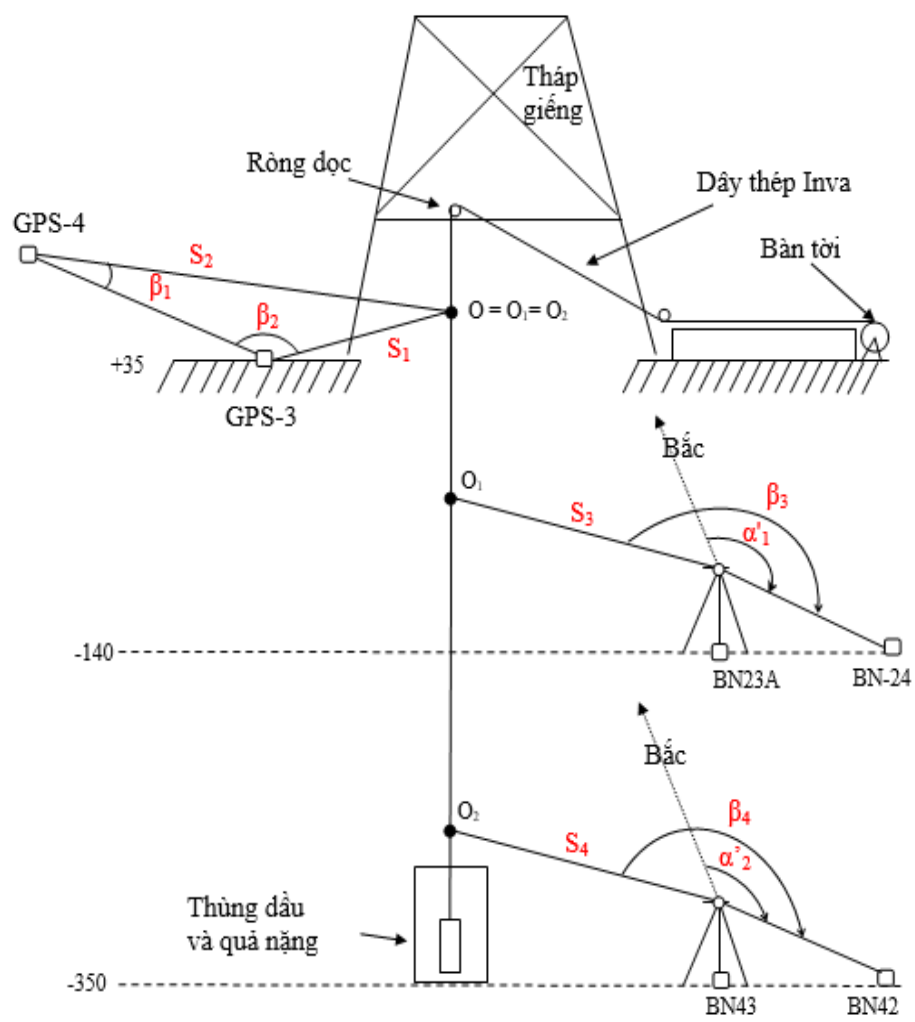

Hình 3. Sơ đồ đo liên hệ mặt bằng qua giếng đứng tại mỏ than Núi Béo. 
-140 m và -350 m, các giá trị này được sử dụng để thành lập đường chuyền cấp 2 hầm lò nối từ giếng đứng tại hai mức này tới cửa giếng nghiêng $+20 \mathrm{~m}$ cánh Đông của mỏ. Đường chuyền cấp 2 gồm hai nhánh đường chuyền có chiều dài 2388,293 m và 1986,393 m với sơ đồ như Hình 4.
Công tác đo góc cạnh đường chuyền cấp 2 được thực hiện theo đúng tiêu chuẩn (Tập đoàn Công nghiệp Than - Khoáng sản Việt Nam, 2015). Bình sai lưới theo phương pháp bình sai chặt chẽ được các kết quả đánh giá độ chính xác lưới: sai số vị trí điểm yếu nhất $+15 \mathrm{~cm}$ và sai số trung phương phương vị cạnh yếu nhất là 9,23".

Bảng 2. Kết quả xác định độ lệch tù thiên tại khu vực thực nghiệm.

\begin{tabular}{|c|c|c|c|}
\hline Cạnh đo & Phương vị con quay & Phương vị thực & Độ lệch từ thiên $(\delta)$ \\
\hline GPS4 -GPS3 & $191^{\circ} 42^{\prime} 45^{\prime \prime}$ & $191^{\circ} 45^{\prime} 53^{\prime \prime}$ & - 00 `03'08” \\
\hline
\end{tabular}

Bảng 3. Kết quả xác định phương vị cạnh dưới hầm lò.

\begin{tabular}{|c|c|c|c|}
\hline Cạnh đo & Phương vị con quay & Độ lệch từ thiên & Phương vị cạnh \\
\hline \multicolumn{4}{|l|}{ Mức $-140 \mathrm{~m}$} \\
\hline BN23A - BN24 & 159॰37'07' & $-00^{\circ} 03^{\prime} 08^{\prime \prime}$ & 159०33'59" \\
\hline $\mathrm{BN} 23 \mathrm{~A}-\mathrm{O}_{1}$ & 189॰11'06" & $-00^{\circ} 03^{\prime} 08^{\prime \prime}$ & $189^{\circ} 07^{\prime} 58^{\prime \prime}$ \\
\hline \multicolumn{4}{|l|}{ Mức -350 m } \\
\hline $\mathrm{BN} 43-\mathrm{BN} 42$ & 170॰58'43” & $-00^{\circ} 03^{\prime} 08^{\prime \prime}$ & 171'55’35" \\
\hline $\mathrm{BN} 43-\mathrm{O}_{2}$ & 34०39'19" & $-00^{\circ} 03^{\prime} 08^{\prime \prime}$ & $340^{\circ} 36^{\prime} 11^{\prime \prime}$ \\
\hline
\end{tabular}

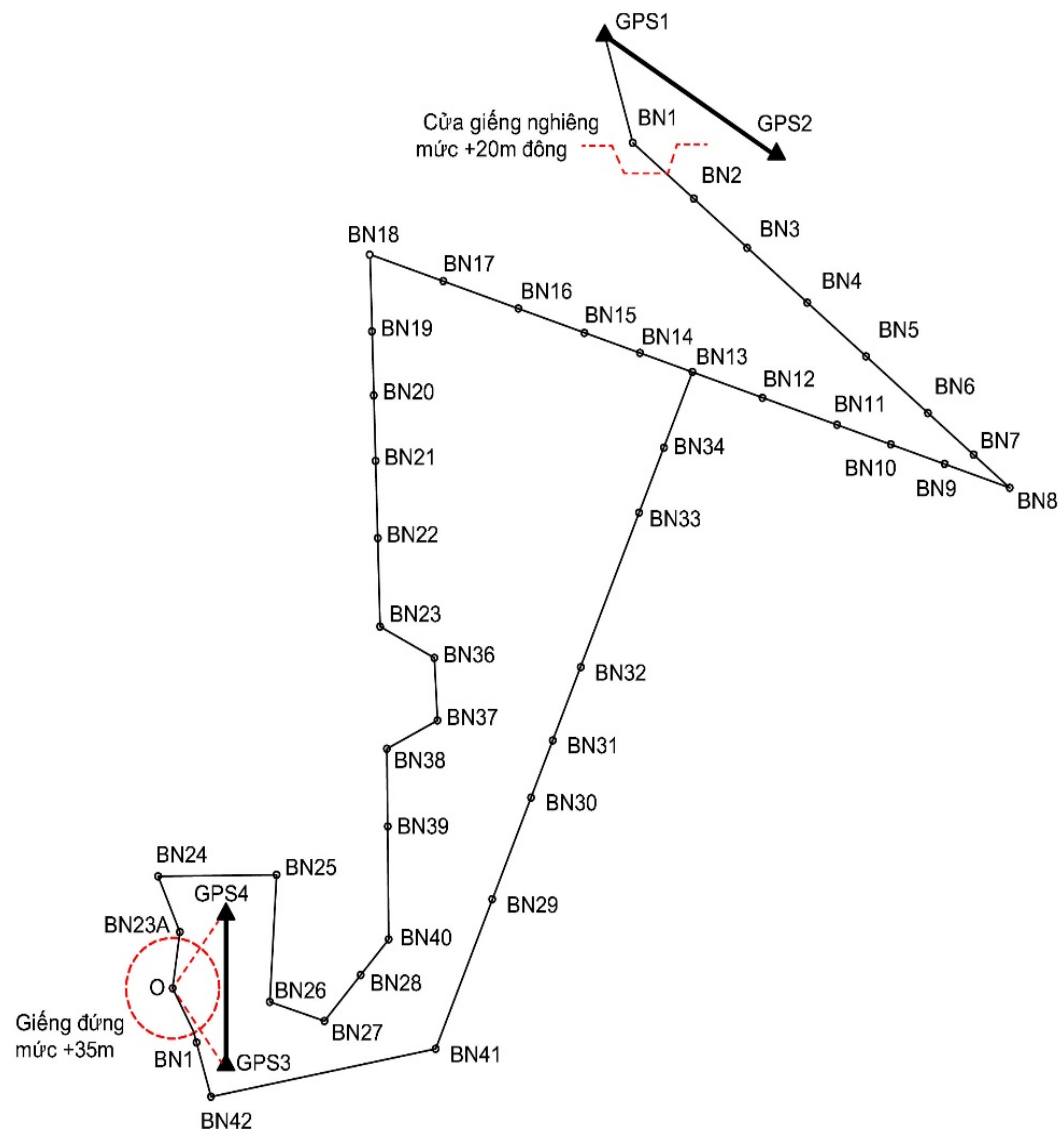

Hình 4. Sơ đồ lưới đường chuyền 2 mỏ than Núi Béo. 


\section{Thảo luận}

Theo nguyên lý đo góc phương vị bằng máy kinh vĩ con quay tại mục 2 và thực nghiệm tại mục 3.3, tại cùng một vị trí đo, góc phương vị từ được coi là như nhau. Độ lệch từ thiên $(\delta)$ tính toán để hiệu chỉnh tìm ra góc phương vị của cạnh dưới hầm lò trong cùng một khu vực đo đạc được coi là như nhau. Do vậy, mặc dù các cạnh (BN23A$\mathrm{BN} 24)$ và (BN42-BN43) ở các mức đường lò khác nhau $(-140 \mathrm{~m}$ và $-350 \mathrm{~m})$ nhưng sai số đo góc phương vị bằng máy kinh vĩ con quay (cùng thiết bị đo, cùng phương pháp đo) có thể coi là như nhau, không phụ thuộc vào chiều sâu đường lò.

Việc ứng dụng máy kinh vĩ con quay để xác định phương vị cạnh đầu tiên cho lưới hầm lò đã cho kết quả tin cậy. Đường chuyền cấp 2 được thành lập với chiều dài trên $2 \mathrm{~km}$, sai số phương vị cạnh yếu nhất là 9,23" và vị trí điểm yếu nhất là $\pm 15 \mathrm{~cm}$. Trong khi đó, nếu sử dụng phương pháp truyền thống để chuyền phương vị xuống lò, sai số vị trí điểm thông lò có thể lên tới $2,4 \mathrm{~m}$ với đường lò có chiều dài gần $2 \mathrm{~km}$ (Lê Văn Cảnh, Nguyễn Viết Nghĩa, 2016). Từ đó, cho thấy ứng dụng máy kinh vĩ con quay xác định phương vị cạnh đầu tiên cho lưới hầm lò đã nâng cao được độ chính xác của lưới đường chuyền hầm lò.

Ngoài ra, từ phương pháp đo thực nghiệm trên Hình 3 , góc phương vị cạnh của lưới hầm lò $\left(\alpha_{1}^{\prime} v\right.$ à $\left.\alpha_{2}^{\prime}\right)$ được đo độc lập bằng máy kinh vĩ con quay không cần phải có dây quả nặng để đo giá trị này. Dây quả nặng chỉ có tác dụng tính chuyền tọa độ cho điểm đầu tiên của lưới hầm lò. Do đó, khi xác định phương vị bằng máy kinh vĩ con quay không chịu ảnh hưởng của sai số chiếu điểm

\section{Kết luận}

Kết quả ứng dụng máy kinh vĩ con quay đo chuyền phương vị lưới khống chế toạ độ phẳng hầm lò mỏ than Núi Béo đã cho phép rút ra các kết luận sau đây:

- Ứng dụng máy kinh vĩ con quay xác định phương vị cạnh đầu tiên của lưới hầm lò tại mỏ than Núi Béo đạt độ chính xác theo Tiêu chuẩn Trắc địa mỏ.

- Độ chính xác chuyền phương vị qua giếng đứng bằng máy kinh vĩ con quay không phụ thuộc vào độ chính xác chiếu điểm.

- Độ chính xác của phương pháp định hướng bằng kinh vĩ con quay không phụ thuộc vào độ sâu của giếng. Nghĩa là, độ sâu lớn của các giếng đứng trên bể than Quảng Ninh không ảnh hưởng đến độ chính xác khi chuyền phương vị bằng máy kinh vĩ con quay.

- Hiệu quả kỹ thuật nổi trội của phương pháp: Hiệu quả kinh tế là giảm thời gian, công sức và nâng cao mức độ an toàn lao động trong giếng mỏ. Thời gian ngừng giếng đứng rất ngắn góp phần nâng cao hiệu quả kinh tế của phương pháp.

\section{Lò̀i cảm ơn}

Bài báo này là sản phẩm khoa học của đề tài cơ sở mã số T20-07, nhóm tác giả chân thành cảm ơn Trường đại học Mỏ - Địa chất đã hỗ trợ kinh phí, cảm ơn Công ty CP than Núi Béo đã hỗ trợ trong quá trình đo đạc thực nghiệm tại mỏ.

\section{Đóng góp của các tác giả}

Võ Ngọc Dũng - lập dàn ý, viết nội dung phần thực nghiệm và biên tập bài báo; Lê Văn Cảnh viết phần mở đầu, nguyên lý đo phương vị con quay, phân tích số liệu và phần thảo luận; Nguyễn Tiến Dụng và Nguyễn Anh Tú - đo đạc thực địa.

\section{Tài liệu tham khảo}

Công ty cổ phần Địa chất Mỏ. (2020). Báo cáo kỹ thuật thành lập lưới khống chế hầm lò mỏ than Núi Béo-Vinacomin.

Černota, P., Staňková, H., Brejcha, M., \& Bouček, L. (2013). Application of the New Mine Surveying Methods for Purposes of the Longest Crosscutting in the Czech Republic. Recent advances in energy, environment and geology, 8-10.

Lê, V. C., \& Nguyễn, V. N. (2014). Nâng cao hiệu quả công tác định hướng qua giếng đứng có độ sâu lớn tại mỏ Hà Lầm. Công nghiệp mỏ, 3, 66-69.

Lê, V. C., \& Nguyễn, V. N. (2016). Giải pháp nâng cao độ chính xác thông hướng giữa hai giếng đứng có độ sâu lớn ở mỏ Hà Lầm, Tạp chí Công nghiệp mỏ, 4, 29-33.

Jabłoński, M. (2019). The use of telemetric measuring methods to determine deformation of the shaft pipe and shaft towers. Przegad Gorniczy.

Nguyễn, Đ. B., Võ, C. M., \& Nguyễn, X. T. (1998). Trắc địa mỏ. Nhà Xuất bản Giao thông Vận tải. 
Nguyễn, V. N., \& Võ, N. D. (2016). Đánh giá độ chính xác vị trí điểm lưới khống chế hầm lò mỏ Hà Lầm khi đo phương vị bằng kinh vĩ con quay. Khoa học kỹ thuật Mỏ - Địa chất, 55, 5559.

Phạm, C. K. (2013). Nghiên cứu giải pháp nâng cao độ chính xác đo định hướng qua giếng đứng. Tạp chí Công nghiệp Mỏ, 2, 11-14.

Tập đoàn Công nghiệp Than - Khoáng sản Việt Nam. (2015). TCVN 10673:2015 về Trắc địa Mỏ (Vol. 1). Bộ Khoa học và Công nghệ Việt Nam.

Topcon, (2021). Sokkia Automated Gyro Station GYRO $X$ determines azimuth quickly, with precision - Technology ideal for tunneling, pipelines, and shipbuilding.

Võ, C. M. (2016). Trắc địa mỏ. Nhà xuất bản Khoa học Tự nhiên và Công nghệ.

Võ, C. M., \& Lê, V. C. (2013). Các nguồn sai số ảnh hưởng đến độ chính xác xác định tọa độ và phương vị khi định hướng qua hai giếng đứng. Công nghiệp mỏ, 2B, 04-06.

Võ, N. D., \& Nguyễn, T. D. (2020). Hiệu quả ứng dụng máy kinh vĩ con quay xác định phương vị đo định hướng mặt bằng lưới khống chế mỏ hầm lò Núi Béo. Hội nghị Khoa học - Công nghệ mỏ toàn quốc, Việt Nam. 